\title{
The acute effect of dietary monounsaturated fatty acids on arterial stiffness
}

\author{
F. E. Lithander, L. K. Herlihy, D. Walsh, E. Burke and A. Mahmud \\ School of Medicine, Trinity College Dublin, Dublin, Republic of Ireland
}

\begin{abstract}
Arterial stiffness is an established cardiovascular (CV) risk factor and associated with overall and CV mortality ${ }^{(1)}$. Acute dietary interventions such as alcohol reduce arterial stiffness ${ }^{(2)}$ while caffeine increases $i^{(3)}$. Only one study has investigated the acute effect of dietary fat on arterial stiffness ${ }^{(4)}$ whereas the differential effect of dietary fatty acids on arterial stiffness has received little attention. The aim of the current study was to investigate the acute postprandial effect of dietary monounsaturated fatty acids (MUFA) on arterial stiffness.

Twenty healthy males (BMI 24, $2 \mathrm{~kg} / \mathrm{m}^{2}$; age 37.7, $14.4 \mathrm{y}$ (mean, SD)) participated in this single-blind, randomised, cross-over study. All subjects had normal fasting plasma glucose, were normotensive with no evidence of hyperlipidaemia. Each subject was given a highfat test-meal ( $3 \mathrm{MJ} ; 54,1 \mathrm{~g}$ fat (mean, SD); $67.5 \%$ of energy as fat) at breakfast on 2 occasions, one rich in MUFA (MUFA high ) and one low in MUFA (MUFA ${ }_{\text {low }}$ ). Blood pressure and arterial stiffness (pulse wave velocity (PWV) and augmentation index (AIx)) were measured in the supine position using applanation tonometry at baseline ( 0 minutes) and at 30, 60, 90, 120, 150, 180, 210 and 240 minutes after the start of the ingestion of the test-meals. Subjects remained sedentary during each dietary intervention period.

There was no significant difference in PWV, AIx or blood pressure at baseline between the two dietary treatments $(P>0.05)$. Overall, there was a small but significant increase in PWV (time, $P<0.05)$ and a significant decrease in AIx over time (time, $P<0.05)$. There were no differential effects of fatty acid saturation over time on PWV, AIx, AIx75 (AIx corrected for heart rate of 75 bpm) or blood pressure (treatment*time, $P>0.05$ ).

Whilst there was no evidence in the current study to suggest that a meal rich in MUFA improves arterial stiffness compared to an isoenergetic meal with lower MUFA content, further research is necessary to understand the interaction between dietary fatty acids and arterial stiffness in the postprandial state.
\end{abstract}

This work was supported by an Irish Heart Foundation Noel Hickey Research Bursary.

1. Laurent S, Boutouyrie P, Asmar R, Gautier I et al. (2001) Hypertension 37, 1236-41.

2. Mahmud A \& Feely J (2002) Am J Hypertens 15, 240-3.

3. Swampillai J, Rakebrandt F, Morris K, Jones CJ et al. (2006) Eur J Clin Invest 36, 844-9.

4. Nestel PJ, Shige H, Pomeroy S, Cehun M et al. (2001) J Am Coll Cardiol 37, 1929-35. 